Original Article

\title{
CONICITY INDEX OF ADULT BANGLADESHI POPULATION AND THEIR SOCIO-DEMOGRAPHIC CHARACTERISTICS
}

\author{
Meerjady Sabrina Flora ${ }^{1}$, CGN Mascie-Taylor ${ }^{2}$, Mahmudur Rahman ${ }^{3}$ \\ ${ }^{1}$ Department of Epidemiology, NIPSOM, Mohakhali, Dhaka \\ ${ }^{2}$ Department of Biological Anthropology, University of Cambridge, United Kingdom \\ ${ }^{3}$ Department of Epidemiology, IEDCR, Mohakhali, Dhaka
}

\begin{abstract}
In spite of acknowledged importance, no unified definition exists for central obesity. Several anthropometric indexes such as waist circumference, waist-hip ratio, waist-to-height ratio, conicity index etc, are being used. Cindex has been shown to correlate well with various cardiovascular risk factors associated with visceral fat accumulation in some population. Data were collected through interviewing and measuring 22,995 adult males and females of an urban (Mirpur, Dhaka City) and rural area (Kaliganj sub-district) in 2002 and 2003. Overall the mean (SD) conicity index was 1.20 (0.10) and $40.8 \%$ of this sample had a high Cindex. Females, increasing age, urban residents, Christians, the better educated, married and farmers were more likely to have higher Cindex than their counterparts. There is a scarcity of data about the conicity index of Bangladeshis and this cross-sectional study is the first large-scale attempt. So it can be used as a baseline data for further research in this field.
\end{abstract}

Ibrahim Med. Coll. J. 2009; 3(1): 1-8

Key words: Conicity index, socio-demography, Bangladeshi

\section{Introduction}

Anthropometry is the single most universally applicable, inexpensive, and non-invasive method available to assess the size, proportion, and composition of the human body. ${ }^{1}$ It is being increasingly recognised that central obesity, rather than general, is likely to coexist with type 2 diabetes and lead to complications including cardiovascular diseases. If abdominal obesity is more predictive of multiple risk factors, it is necessary to determine a suitable and widely accepted parameter for this kind of obesity as Body Mass Index is for general obesity. But in spite of its acknowledged importance, no unified definition exists for central obesity; several anthropometric indexes such as waist circumference (WC), waist-hip ratio (WHR), waist-to-height ratio (WHtR), conicity index (Cindex) etc, are being used. ${ }^{2}$ There is no universally agreed way of measuring adiposity, nor is it known which measure is the best predictor of cardiovascular disease. BMI, WC, WHR, WHtR, Cindex all are found to associate with cardiovascular risk factors. ${ }^{3}$ Valdez et al. (1993) proposed that 'the conicity index (Cindex) seems to be a viable approach to assess abdominal adiposity and its concomitant health risks in large-scale studies. ${ }^{4}$ Cindex has been shown to correlate well with various cardiovascular risk factors associated with visceral fat accumulation in some population. ${ }^{4,5}$ Cindex showed the highest correlation with total cholesterol, and low density lipoproteins (LDL) in a study by Yasmin \& MascieTaylor (2003). ${ }^{3}$ There was evidence that the central obesity indices, especially Cindex and WHR, are better at discriminating High Coronary Risk (HCR) than of general obesity (BMI). The largest area under the Receiver Operating Characteristics (ROC) curve

Address for Correspondence:

Dr. Meerjady Sabrina Flora, Associate Professor, Department of Epidemiology, National Institute of Preventive and Social Medicine (NIPSOM), Mohakhali, Dhaka.e-mail: flora@citechco.net 
was found between Cindex and HCR, in males, which was significantly different from other obesity indices. In women, the largest area found under the ROC curve was equally between Cindex, WHR and HCR indices. ${ }^{6}$

A person having a Cindex of 1.25 means s/he has a waist circumference which is 1.25 times larger than the circumference of a cylinder with height and weight of that person. The predicted range of Cindex is between 1.00 (perfect cylinder) and 1.73 (perfect double cone). The best cut-off points for discrimination of high coronary risk in adult men and women of Salvador, Brazil were, respectively 1.25 (73.91\% sensitivity and $74.92 \%$ specificity) and 1.18 (73.39\% sensitivity and $61.15 \%$ specificity). ${ }^{6}$ Greater conicity in Asian young adults of both sexes, than in Europeans, was observed in the top tertiles of weight and BMI. ${ }^{7}$ Cindex is more variable in women than men. ${ }^{4}$

No study, so far, has been conducted to assess the central obesity of Bangladeshi population using conicity index. This study is the first attempt to do so.

\section{Materials and Methods}

This was a cross-sectional study. Data were collected through interviewing 22,995 adult males and females of an urban (Mirpur, Dhaka City) and rural area (Kaliganj sub-district) in 2002 and 2003. Every alternate household which fulfilled the selection criteria (at least one male and one female $\geq 18$ years were available), were recruited. A pre-tested structured questionnaire printed in Bangla was used for data collection. Anthropometric measurements were taken using validated equipment based on standard procedures. ${ }^{\mathbf{3}}$ Verbal consent was obtained from every respondent and interviews were held in a private place. Ethical clearance was obtained from the Institutional Ethical Committee.

Subjects were measured wearing minimal attire. All the equipments were checked regularly to minimise random errors. Height was measured to the nearest $0.1 \mathrm{~cm}$ with a specially constructed wooden height stand to which a plastic measuring tape was attached. The subject stood without shoes or head gear (cap, ribbon etc) in an upright posture with their head in the Frankfurt plane. Subjects were asked to keep their heels close together with their hands hanging freely by their side, palms facing inwards. The horizontal blade of the stadiometer was gently placed on the crown of the head to take the measurement. Weight was measured using a bathroom scale accurate to 0.5 $\mathrm{kg}$ with the subject wearing minimal attire. The scale was placed on a hard flat surface and the subject was requested to step onto it in bare feet without holding onto anything. The weighing scale was set to zero before every measurement. A flexible plastic tape was used to measure waist circumference, accurate up to the nearest $0.1 \mathrm{~cm}$. Waist circumference was measured at the level mid way between the lowest rib margin and the superior iliac crest on the midaxillary line in a horizontal plane. The subjects stood erect with abdomen relaxed, the arms at the side and feet together and breathing normally.

Cindex was constructed using the following formula:

Cindex $=$ Waist Circumference $(\mathrm{m}) /[0.109 \mathrm{X} \sqrt{ }$ \{Body weight (kg)/ Height (m)\}]

where 0.109 is a constant which results from the conversion of units of volume and mass into units of length. ${ }^{4}$ For male 1.25 and for females 1.18 cut-offs were used to classify Cindex into normal and high categories.

The analyses were carried out primarily using the Statistical Package for Social Sciences (SPSS) version 14.0. Statistical tests used to determine the association between exposure and outcome variables included $\chi^{2}$ test and Student t-test. A result was considered significant at a $\mathrm{p}$ value level $<0.05$ but given the large sample sizes a more stringent cut-off of $\mathrm{p}<0.01$, or less, was usually used. In addition because a number of statistical tests were conducted, the Bonferroni correction $(\alpha / K$, where $\alpha$ is the $p$ value $\& K$ is the number of tests used) was used. Effects of exposure variables were also assessed after adjusting for other variables by multivariate analyses.

\section{Result}

Overall, the mean (SD) conicity index was $1.20(0.10)$ but there was considerable heterogeneity in relation to socio-demographic status. Age and sex adjustments were made before taking into account each of the other socio-demographic variables (Table-1). Except for religion all other socio-demographic variables were found to associate with Cindex. Urban residents, Christians, widows/divorcees, less educated and the non-paid had, on average, a higher Cindex than their counterparts. 
Table-1: Conicity Index in Relation to the Socio-demographic Variables

\begin{tabular}{|c|c|c|c|c|c|c|c|c|}
\hline \multirow[t]{2}{*}{ Variables } & \multirow[t]{2}{*}{$\mathbf{N}$} & \multirow[t]{2}{*}{ Mean } & \multirow[t]{2}{*}{ SD } & \multirow[t]{2}{*}{$\mathbf{F}$} & \multirow[t]{2}{*}{ p-value } & \multicolumn{3}{|c|}{$\begin{array}{c}\text { Adjusted for Other } \\
\text { Socio-demographic Variables }\end{array}$} \\
\hline & & & & & & B & F-change & $p$-value \\
\hline \multicolumn{9}{|l|}{$\overline{\text { Sex }}$} \\
\hline Male* & 10456 & 1.18 & 0.09 & \multirow{3}{*}{$\begin{array}{l}-17.9^{\mathrm{a}} \\
567.7^{\wedge}\end{array}$} & \multirow{3}{*}{$\begin{array}{l}<0.001 \\
<0.001\end{array}$} & & \multirow{3}{*}{257.6} & \multirow{3}{*}{$<0.001$} \\
\hline Female & 12539 & 1.21 & 0.11 & & & .034 & & \\
\hline Total & 22995 & 1.20 & 0.10 & & & & & \\
\hline \multicolumn{9}{|l|}{ Age in Years } \\
\hline$<20^{*}$ & 2507 & 1.15 & 0.09 & \multirow{8}{*}{$1007.7 \dagger$} & \multirow{8}{*}{$<0.001$} & & \multirow{8}{*}{180.6} & \multirow{8}{*}{$<0.001$} \\
\hline $20-29$ & 7356 & 1.18 & 0.10 & & & .018 & & \\
\hline $30-39$ & 4949 & 1.20 & 0.09 & & & .044 & & \\
\hline $40-49$ & 3720 & 1.22 & 0.09 & & & .060 & & \\
\hline $50-59$ & 2249 & 1.23 & 0.10 & & & .074 & & \\
\hline $60-69$ & 1397 & 1.24 & 0.11 & & & .091 & & \\
\hline $70 \&$ above & 817 & 1.23 & 0.10 & & & .089 & & \\
\hline Total & 22995 & 1.20 & 0.10 & & & & & \\
\hline \multicolumn{9}{|l|}{ Area } \\
\hline Rural* & 11789 & 1.19 & 0.09 & \multirow{3}{*}{$172.1^{v}$} & \multirow{3}{*}{$<0.001$} & \multirow{3}{*}{.015} & \multirow{3}{*}{106.1} & \multirow{3}{*}{$<0.001$} \\
\hline Urban & 11206 & 1.20 & 0.11 & & & & & \\
\hline Total & 22995 & 1.20 & 0.10 & & & & & \\
\hline Religion & & & & & & & & \\
\hline Islam* & 21445 & 1.20 & 0.10 & & & & & \\
\hline Hinduism & 1215 & 1.20 & 0.09 & & & & & \\
\hline Christianity & 333 & 1.21 & 0.10 & $2.8^{\vee}$ & ns & .015 & 5.6 & 0.004 \\
\hline Total & 22993 & 1.20 & 0.10 & & & & & \\
\hline Marital Status & & & & & & & & \\
\hline Married* & 17885 & 1.20 & 0.10 & & & & & \\
\hline Unmarried & 4078 & 1.15 & 0.08 & & & -.014 & & \\
\hline Widow/ Divorced & 1031 & 1.22 & 0.12 & $36.7^{v}$ & $<0.001$ & -.012 & 25.3 & $<0.001$ \\
\hline Total & 22994 & 1.20 & 0.10 & & & & & \\
\hline Educational Status & & & & & & & & \\
\hline No Schooling* & 6477 & 1.20 & 0.10 & & & & & \\
\hline $1-5$ yrs of Schooling & 5044 & 1.20 & 0.10 & & & .009 & & \\
\hline 6-10 yrs of Schooling & 8067 & 1.19 & 0.10 & $84.5^{\vee}$ & $<0.001$ & .017 & 54.6 & $<0.001$ \\
\hline Higher Secondary + & 3402 & 1.19 & 0.10 & & & .031 & & \\
\hline Total & 22990 & 1.20 & 0.10 & & & & & \\
\hline Occupation & & & & & & & & \\
\hline Non-paid* & 11042 & 1.21 & 0.11 & & & & & \\
\hline Students & 1597 & 1.15 & 0.08 & & & -.022 & & \\
\hline Manual Labourer & 575 & 1.16 & 0.07 & & & -.014 & & \\
\hline Farmer & 2660 & 1.20 & 0.08 & & & .011 & & \\
\hline Skilled Labourer & 886 & 1.17 & 0.08 & $12.2^{v}$ & $<0.001$ & -.010 & 15.7 & $<0.001$ \\
\hline Business & 2526 & 1.19 & 0.09 & & & .002 & & \\
\hline Service/ Professionals & 3575 & 1.19 & 0.10 & & & -.006 & & \\
\hline Total & 22861 & 1.20 & 0.10 & & & & & \\
\hline
\end{tabular}

*Reference Group; ${ }^{a} t$-test before Adjustment ${ }^{\wedge}$ Age Adjusted; $†$ Sex Adjusted; ${ }^{\vee}$ Age and Sex Adjusted

Sequential multiple regression analyses were also undertaken to determine the effect of each sociodemographic variable after correcting for all the other socio-demographic variables. The full model was significant $(F=133.3 ; p<0.001)$ but only explained $10.8 \%$ of the variance in Cindex. After adjustment 
Table-2: Conicity Index Categories in Relation to the Socio-demographic Variables

\begin{tabular}{|c|c|c|c|c|c|c|c|c|}
\hline \multirow{3}{*}{ Variables } & \multicolumn{4}{|c|}{ Conicity Index* } & \multirow{2}{*}{\multicolumn{2}{|c|}{ Total }} & \multirow{3}{*}{$\chi^{2}$} & \multirow{3}{*}{ p-value } \\
\hline & \multicolumn{2}{|c|}{ Normal } & \multicolumn{2}{|c|}{ High } & & & & \\
\hline & $\mathbf{n}$ & $\%$ & $\mathbf{n}$ & $\%$ & $\mathbf{n}$ & $\%$ & & \\
\hline \multicolumn{9}{|l|}{ Area } \\
\hline Rural & 7359 & 62.4 & 4430 & 37.6 & 11789 & 51.3 & \multirow{3}{*}{101.8} & \\
\hline Urban & 6262 & 55.9 & 4944 & 44.1 & 11206 & 48.7 & & $<0.001$ \\
\hline Total & 13621 & 59.2 & 9374 & 40.8 & 22995 & 100.0 & & \\
\hline \multicolumn{9}{|l|}{ Sex } \\
\hline Male & 8188 & 78.3 & 2268 & 21.7 & 10456 & 45.5 & \multirow{3}{*}{2889.2} & \multirow{3}{*}{$<0.001$} \\
\hline Female & 5433 & 43.3 & 7106 & 56.7 & 12539 & 54.5 & & \\
\hline Total & 13621 & 59.2 & 9374 & 40.8 & 22995 & 100.0 & & \\
\hline \multicolumn{9}{|l|}{ Age in years } \\
\hline$<20$ & 1900 & 75.8 & 607 & 24.2 & 2507 & 10.9 & \multirow{8}{*}{721.9} & \multirow{8}{*}{$<0.001$} \\
\hline $20-29$ & 4753 & 64.6 & 2603 & 35.4 & 7356 & 32.0 & & \\
\hline $30-39$ & 2939 & 59.4 & 2010 & 40.6 & 4949 & 21.5 & & \\
\hline $40-49$ & 1841 & 49.5 & 1879 & 50.5 & 3720 & 16.2 & & \\
\hline $50-59$ & 1082 & 48.1 & 1167 & 51.9 & 2249 & 9.8 & & \\
\hline $60-69$ & 665 & 47.6 & 732 & 52.4 & 1397 & 6.1 & & \\
\hline $70 \&$ above & 441 & 54.0 & 376 & 46.0 & 817 & 3.6 & & \\
\hline Total & 13621 & 59.2 & 9374 & 40.8 & 22995 & 100.0 & & \\
\hline Geometric Mean \pm SD & \multicolumn{2}{|c|}{$31.05 \pm 14.68$} & \multicolumn{2}{|c|}{$35.66 \pm 15.24$} & \multicolumn{2}{|c|}{$32.85 \pm 15.10$} & $-26.0^{\wedge}$ & $<0.001$ \\
\hline \multicolumn{9}{|l|}{ Religion } \\
\hline Islam & 12680 & 59.1 & 8765 & 40.9 & 21445 & 93.3 & \multirow{4}{*}{6.8} & \\
\hline Hinduism & 756 & 62.2 & 459 & 37.8 & 1215 & 5.3 & & $\mathrm{~ns}^{\circ}$ \\
\hline Christianity & 184 & 55.3 & 149 & 44.7 & 333 & 1.4 & & \\
\hline Total & 13620 & 59.2 & 9373 & 40.8 & 22993 & 100.0 & & \\
\hline \multicolumn{9}{|l|}{ Marital Status } \\
\hline Married & 9975 & 55.8 & 7910 & 44.2 & 17885 & 77.8 & \multirow{4}{*}{989.6} & $<0001$ \\
\hline Unmarried & 3252 & 79.7 & 826 & 20.3 & 4078 & 17.7 & & $<0.001$ \\
\hline Widow/ Divorced & 393 & 38.1 & 638 & 61.9 & 1031 & 4.5 & & \\
\hline Total & 13620 & 59.2 & 9374 & 40.8 & 22994 & 100.0 & & \\
\hline Educational Status & & & & & & & & \\
\hline No Schooling & 3616 & 55.8 & 2861 & 44.2 & 6477 & 28.2 & & \\
\hline 1-5 yrs of Schooling & 2965 & 58.8 & 2079 & 41.2 & 5044 & 21.9 & & \\
\hline 6-10 yrs of Schooling & 4880 & 60.5 & 3187 & 39.5 & 8067 & 35.1 & 60.6 & $<0.001$ \\
\hline Higher Secondary + & 2155 & 63.3 & 1247 & 36.7 & 3402 & 14.8 & & \\
\hline Total & 13616 & 59.2 & 9374 & 40.8 & 22990 & 100.0 & & \\
\hline Occupation & & & & & & & & \\
\hline Non-paid & 4810 & 43.6 & 6232 & 56.4 & 11042 & 48.3 & & \\
\hline Students & 1248 & 78.1 & 349 & 21.9 & 1597 & 7.0 & & \\
\hline Manual Labourer & 514 & 89.4 & 61 & 10.6 & 575 & 2.5 & 2294.0 & $<0.001$ \\
\hline Farmer & 2054 & 77.2 & 606 & 22.8 & 2660 & 11.6 & & \\
\hline Skilled Labourer & 670 & 75.6 & 216 & 24.4 & 886 & 3.9 & & \\
\hline Business & 1799 & 71.2 & 727 & 28.8 & 2526 & 11.0 & & \\
\hline Service/ Professionals & 2431 & 68.0 & 1144 & 32.0 & 3575 & 15.6 & & \\
\hline Total & 13526 & 59.2 & 9335 & 40.8 & 22861 & 100.0 & & \\
\hline
\end{tabular}

*Conicity Index Cut-off: 1.25 for male and 1.18 for females; ${ }^{\wedge} t$-test; ${ }^{\circ}$ Bonferroni Corrected 
Conicity index of Bangladeshi population $\mathbf{0 5}$

Table-3: Socio-demographic Predictors of Conicity Index Categories: Sequential Logistic Regression Analysis Adjusted for the Other Socio-demographic Variables

\begin{tabular}{|c|c|c|c|c|}
\hline \multirow[t]{2}{*}{ Variables } & \multicolumn{2}{|c|}{$\begin{array}{c}\text { Adjusted for Other } \\
\text { Socio-demographic Variables }\end{array}$} & \multirow[t]{2}{*}{ Odds Ratio } & \multirow{2}{*}{$\begin{array}{l}95 \% \text { CI for } \\
\text { Odds Ratio }\end{array}$} \\
\hline & $\chi^{2}$ & p-value & & \\
\hline \multicolumn{5}{|l|}{ Area } \\
\hline Rural* & 196.0 & $<0.001$ & & \\
\hline Urban & & & 1.667 & $1.551-1.792$ \\
\hline \multicolumn{5}{|l|}{ Sex } \\
\hline Male* & 1477.2 & $<0.001$ & & \\
\hline Female & & & 7.542 & $6.760-8.415$ \\
\hline \multicolumn{5}{|l|}{ Age in Years } \\
\hline$<20 *$ & 893.5 & $<0.001$ & & \\
\hline $20-29$ & & & 1.326 & $1.171-1.502$ \\
\hline $30-39$ & & & 2.444 & $2.121-2.817$ \\
\hline $40-49$ & & & 3.553 & $3.065-4.117$ \\
\hline $50-59$ & & & 4.601 & $3.913-5.410$ \\
\hline $60-69$ & & & 6.277 & $5.221-7.547$ \\
\hline $70 \&$ above & & & 7.068 & $5.714-8.742$ \\
\hline \multicolumn{5}{|l|}{ Religion } \\
\hline Islam* & 7.2 & $\mathrm{~ns}^{\circ}$ & & \\
\hline Hinduism & & & 0.988 & $0.863-1.131$ \\
\hline Christianity & & & 1.414 & $1.096-1.825$ \\
\hline \multicolumn{5}{|l|}{ Marital Status } \\
\hline Married* & 56.6 & $<0.001$ & & \\
\hline Unmarried & & & 0.673 & $0.593-0.765$ \\
\hline Widow/ Divorced & & & 0.727 & $0.628-0.842$ \\
\hline \multicolumn{5}{|l|}{ Educational Status } \\
\hline No Schooling* & 157.9 & $<0.001$ & & \\
\hline 1-5 yrs of Schooling & & & 1.185 & $1.085-1.295$ \\
\hline $6-10$ yrs of Schooling & & & 1.527 & $1.400-1.665$ \\
\hline Higher Secondary + & & & 1.999 & $1.775-2.252$ \\
\hline \multicolumn{5}{|l|}{ Occupation } \\
\hline Non-paid* & 105.2 & $<0.001$ & & \\
\hline Students & & & 0.613 & $0.510-0.737$ \\
\hline Manual Labourer & & & 0.401 & $0.297-0.542$ \\
\hline Farmer & & & 1.195 & $1.034-1.380$ \\
\hline Skilled Labourer & & & 0.862 & $0.715-1.039$ \\
\hline Business & & & 1.198 & $1.048-1.369$ \\
\hline Service/ Professionals & & & 1.065 & $0.949-1.195$ \\
\hline
\end{tabular}

* Reference Group; CI-Confidence Interval; ${ }^{\circ}$ Bonferroni Corrected

for the other socio-demographic variables it was found that females, increasing age, urban residents, Christians, the better educated, married and farmers were more likely to have a higher Cindex than their counterparts.

Cindex was categorised into 'normal' and 'high' using cut-offs of 1.25 for males and 1.18 for females. ${ }^{6}$ Although considerable variation was found in relation to socio-demographic variables (Table-2), overall
$40.8 \%$ of this sample had a high Cindex. Except for religion all socio-demographic variables were associated with Cindex categories. High Cindex was more common in urban residents, females, and older age groups while it was less common in the unmarried, the better educated and manual labourers.

Sequential binary logistic regression models were used to test the effect of individual socio-demographic variables, after adjusting for the other variables. 
Table-3 shows that the likelihood of high Cindex increased with age and better education. Gender was strongly associated with Cindex; females were 7.5 times more likely to have high Cindex than males. High Cindex was more often found in urban residents, married, farmers and business persons. When all the socio-demographic variables were entered into the model they significantly predicted Cindex $\left(\chi^{2}=4974.2\right.$; $\mathrm{p}<0.001$; Nagelkerke $\left.\mathrm{R}^{2}=.264\right)$ and overall $69.9 \%$ and $76.5 \%$ of normal Cindex, and $60.4 \%$ of high Cindex, were correctly predicted. The forward binary logistic regression revealed sex and age group as the best predictors of Cindex categories. When the analyses were repeated for each sex separately, age was the best predictor of Cindex categories in both sexes, followed by occupation in males and locality in females.

\section{Discussion}

Because of epidemiological transitions, Bangladesh is facing a double burden of health problems; on the one hand the country is not free of communicable diseases and emergence of new infectious diseases, while on the other hand the occurrence of noncommunicable diseases is also increasing. Linked to this epidemiological transition, Bangladesh is also facing a nutrition transition with over-nutrition and under-nutrition occurring simultaneously. While about a quarter of rural, and lower class urban people have chronic energy deficiency; the prevalence of obesity in the upper and middle class urban people is between 9-11\%9. Many countries in this region are going through the so-called "nutrition transition" but collection of good quality national data on obesity as well as under-nutrition are needed. While in some Asian countries the prevalence of obesity is lower than that in Europe, the health risks associated with obesity occur at a lower BMI. ${ }^{10}$ Central obesity is likely to coexist with type 2 diabetes and lead to complications including cardiovascular diseases and it is measured by several anthropometric indexes such as WC, WHR, WHtR, Cindex etc. ${ }^{2}$ Both Cindex and WHR are equivalent as health indicators. Valdez et al. (1993) claimed some advantages of Cindex over WHR: (i) it has a theoretical (expected) range; (ii) it includes a built-in adjustment of waist circumference for height and weight, allowing direct comparisons of abdominal adiposity between individuals or even between populations; and (iii) it does not require the hip circumference to measure fat distribution. ${ }^{4}$ On the contrary, Bose \& Mascie-Taylor (1998) did not find any advantage of Cindex over WHR, as a surrogate for abdominal adiposity ${ }^{11}$. Data from the Charleston Heart Study cohort indicated that while Cindex has a built-in correction for relative weight, it might not adequately control for relative weight where the relationship is quadratic. ${ }^{12}$ A study in India recommended further studies to explore the importance of Cindex in South Asian populations. ${ }^{13}$ Yasmin \& Mascie-Taylor (2000) also suggested more detailed studies should be undertaken before Cindex is used as a surrogate for WHR of abdominal adiposity in both men and women in different population groups. ${ }^{3}$

There is a dearth of adult anthropometric data in Bangladesh other than weight and BMI and most nutrition research has focused on under-nutrition, particularly among women and children. To meet the scarcity of data in regard to Cindex of Bangladeshi population, this study was an attempt to measure the level of Cindex and magnitude of central obesity as classified by the Cindex. The study also observed the variation in Cindex statistically with differences in the socio-demographic status of the Bangladeshi population. This could work as a baseline data for further studies. Given the large sample size of this study, particular care was taken when interpreting 'significant' results and a more stringent cut-off of $\mathrm{p}<0.01$, or less, was usually used. In addition because a number of statistical tests were conducted, the Bonferroni correction $(\alpha / \mathrm{K}$, where $\mathrm{K}$ is the number of tests used) was used to reduce Type I errors. The combination of more stringent $p$ value and correction for the number of test undertaken, lowered the cut-off $\mathrm{p}$ value for significance to $<0.0014$ and most of the $\mathrm{p}$-values were $<0.001$. The magnitude of the difference for statistically significant results was also considered. For example, with a quantitative (continuous) variable a small difference in means might be significant because the standard errors will be small given these sample sizes. However, for a qualitative variable, much larger differences would be required in a chisquare test because the denominator is the expected value, which would be large. Even so, the primary aim of inferential statistics is to generalize from a sample to a population and so the large sample size used here will more closely approximate to the adult Bangladesh population and the $95 \%$ confidence 
intervals will be small. However, this was a crosssectional study and is the simplest form of epidemiological study and so the associations discussed later do not indicate causality. ${ }^{\mathbf{1 4}}$

The overall mean Cindex in the current study was 1.20 and were higher in urban residents. Females had, on average, higher Cindex (1.21 \pm 0.11$)$ than males $(1.18 \pm 0.09)$. The gender difference in mean Cindex could not be compared with any study because of nonavailability. An Indian study ${ }^{15}$ showed that average Cindex of Bengali Adult Hindu male was 1.22 \pm 0.07 which is higher than that of Bangladeshi adult male. But this difference probably is not due to difference in their religion as the current study could not detect any influence of religion on Cindex.

A survey on medical students of United Kingdom showed that females of South Asian descent had a significantly higher conicity index than females of European descent irrespective of how the groups were compared. This difference in conicity was not significant in the male group as a whole, or when ethnic pairs were matched for body weight or body mass index. Male students of South Asian origin in the top tertile for body weight or body mass index had a significantly greater conicity index than European males in these top tertiles. However, the trend towards higher conicity (i.e. abdominal obesity) in young Asians may help explain the higher incidence of diabetes and cardiovascular disease seen in elderly Asians living in the United Kingdom. ${ }^{7}$

Overall $40.8 \%$ of this sample had a high Cindex. Conicity index was categorised into 'normal' and 'high' using cut-offs of 1.25 for males and 1.18 for females. The best cut-off points for discrimination of high coronary risk in adult men and women of Salvador, Brazil were, respectively 1.25 (73.91\% sensitivity and $74.92 \%$ specificity) and 1.18 (73.39\% sensitivity and $61.15 \%$ specificity ${ }^{6}$. Except for religion all sociodemographic variables were associated with the Cindex categories in this study. Cindex is more variable in women than men. ${ }^{4}$ High Cindex increased with age and better education. Gender was strongly associated with Cindex; females were 7.5 times more likely to have high Cindex than males. High Cindex was more often found in urban residents, married, farmers and business persons. The forward binary logistic regression revealed sex and age group as the best predictors of Cindex categories. When the analyses were repeated for each sex separately age was the best predictor of Cindex categories in both sexes, followed by occupation in males and locality in females. For a national cut-off point the sociodemographic differentials need to be considered.

\section{Acknowledgements}

The authors are indebted to the Department for International Development (DfID), United Kingdom, Board of Graduate Studies, the University of Cambridge, The British Federation of Women Graduates Charitable Foundation, The Charles Wallace Bangladesh Trust, and Churchill College, the University of Cambridge for their support.

\section{References}

1. World Health Organization. Physical Status: The Use and Interpretation of Anthropometry. Report of a WHO Expert Committee. Geneva: WHO: 1995.

2. Mamtani MR \& Kulkarni HR. Predictive Performance of Anthropometric Indexes of Central Obesity for the Risk of Type 2 Diabetes. Arch Med Res 2005; 36: 581-589.

3. Yasmin \& Mascie-Taylor CGN. Adiposity Indices and Their Relationship with Some Risk Factors of Coronary Heart Disease in Middle-aged Cambridge Men and Women. Ann Hum Biol 2000; 27: 239-248.

4. Valdez R, Seidell JC, Ahn YI \& Weiss KM. A New Index of Abdominal Adiposity as an Indicator of Risk for Cardiovascular Disease. A Cross-population Study. Int J Obes 1993; 17: 77-82.

5. Muller WH, Meninger JC, Leihr P, Chan W \& Chandler PS. Conicity: A New Index of Body Fat Distribution- What Does It Tell Us? Am J Human Biol 1996; 8: 489-496.

6. Pitanga FJG \& Lessa I. Sensitivity and Specificity of the Conicity Index as a Coronary Risk Predictor among Adults in Salvador, Brazil. Rev Bras Epidemiol 2004; 7: 259-269.

7. Gishen FS, Hogh LM \& Stock MJ. Differences in Conicity in Young Adults of European and South Asian Descent [Short Communication]. Int J Obes 2995; 19: 146-148.

8. Lohman TG, Roche AF \& Martorell R, eds Anthropometric Standardization Reference Manual. Champaign, Illinois: Human Kinetic Books: 1988.

9. Rahman M, Rahman M, Flora MS, Akter SFU, Hossain S \& Mascie-Taylor CGN. Behavioural Risk 
Factors of Non-Communicable Diseases in Bangladesh. Dhaka, 2006a.

10. World Health Organization. Obesity: Preventing and Managing the Global Epidemic: Report of WHO Consultation. WHO Technical Report Series No. 894. Geneva: WHO 2000.

11. Bose K \& Mascie-Taylor CGN. Conicity Index and Waist-Hip-Ratio and Their Relationship with Total Cholesterol and Blood Pressure in Middle-aged European and Pakistani Men. Ann Hum Biol 1998; 25: $11-16$.

12. Stevens J \& Plankey MW. The Conicity Index (letter). Int J Obes 1993; 17: 727.
13. Venkatramana P \& Reddy PC. Association of Overall and Abdominal Obesity with Coronary Heart Disease Risk Factors: Comparison between Urban and Rural Indian Men. Asia Pac J Clin Nutr 2002; 11: 66-71.

14. Cole TJ. Sampling, Study Size, and Power. In: Margetts BM \& Nelson M eds. Design Concepts in Nutritional Epidemiology. $2^{\text {nd }}$ ed. UK: Oxford University Press 2004. p.64-86.

15. Ghosh JR \& Bandyopadhyay AR. Comparative Evaluation of Obesity Measures: Relationship with Blood Pressures and Hypertension. Singapore Med J 2007; 48: 232-235. 